\title{
Temporal trends in vascular trauma in Ontario, 1991-2009: a population-based study
}

\author{
Abdulmajeed Altoijry MD MSc, Mohammed Al-Omran MD MSc, K. Wayne Johnston MD, \\ Muhammad Mamdani PharmD MPH, Thomas F. Lindsay MDCM MSc
}

Abstract

Background: Vascular injuries add substantial complexity to trauma care, yet Canadian epidemiologic data on such injuries are not readily available. We conducted a retrospective cross-sectional study to examine temporal trends in the rate of hospital admissions for vascular injuries from 1991 to 2009 in Ontario.

Methods: Individuals of any age admitted to hospital because of vascular trauma in Ontario were included. Details of vascular injury and patient demographic characteristics were recorded, hospital admission rates estimated and analyses stratified by sex, age, mechanism of injury, economic status and geographic location. Time-series analysis was used to examine trends in hospital admission rates.

Results: Of the 8252 hospital admissions for vascular trauma, 4287 (52.0\%) involved injuries to the upper limb and 1819 (22.0\%) were due to transport-related causes. Overall, the annual rate declined significantly over time, from 3.3 per 100000 in 1991 to 2.7 per 100000 in $2009(p<0.01)$. The subgroups with the highest rates were young men, patients with a low economic status and those living in a rural location. Declines occurred in both sexes and in all age groups except those 65 years and older. The rates of vascular injury to the neck, thorax, upper limbs and lower limbs declined over time, but not the rate of abdominal vascular injury. Although the rate of non-transport-related vascular injuries declined, the rate of transport-related vascular injuries did not change significantly over time. Decreases in annual rates occurred in both low- and high-economic status groups and in urban populations but not in rural populations.

Interpretation: Overall, the annual rate of hospital admissions for vascular trauma declined significantly in Ontario over the study period. Our findings have important implications for public health and the development of injury-prevention strategies, particularly for population subgroups at high risk of vascular injury.

I njuries to the vascular system complicate trauma management and result in substantial morbidity and mortality. A study evaluating the impact of injuries on health in the Netherlands reported that one-third of injuries, including vascular injuries, required admission to hospital and about onethird were fatal. ${ }^{1}$ The burden of injury is generally higher among men aged 25-44 years (accounting for 24\%-46\% of injuries in Europe), with an added risk of premature death. ${ }^{2}$ This burden has a tremendous impact on the quality of life of patients, affecting their ability to work and causing pain, discomfort and substantial disability. ${ }^{3,4}$ Because of the life-threatening nature of vascular injuries, evaluating their temporal incidence with mortality is necessary. Assessment of vascular injury trends associated with different population characteristics can be used to identify groups at a high risk to initiate prevention strategies.

According to the Public Health Agency of Canada, injuries resulted in 13906 deaths in 2003; moreover, the combined economic burden associated with both intentional and unintentional injuries was estimated to be more than $\$ 12.7$ billion per year. ${ }^{5}$ However, data analyses on vascular injury rates in Canada

Competing interests: Muhammad Mamdani has served as an advisory board member for AstraZeneca, Bristol-Myers Squibb, Eli Lilly, GlaxoSmithKline, Novo Nordisk, Pfizer, Hoffmann-La Roche and Novartis. Thomas Lindsay has received consultancy fees from Cook Canada. No other competing interests were declared.

Disclaimer: Muhammad Mamdani is a member of the CMAJ Open Editorial Advisory Board and was not involved in the editorial decision-making process for this article.

This article has been peer reviewed.

Correspondence to: Abdulmajeed Altoijry, abdulmajeed.altoijry@ mail.mcgill.ca

CMAJ Open 2016. DOI:10.9778/cmajo.20150046 
are lacking. We conducted a population-based study to examine trends in the rate of hospital admissions for vascular injuries from 1991 to 2009 in the province of Ontario, Canada.

\section{Methods}

\section{Study design and population}

We conducted a retrospective, population-based, crosssectional time-series study involving patients of all ages in Ontario who were admitted to hospital because of vascular injuries. We restricted the time frame to fiscal years from Apr. 1, 1991, to Mar. 31, 2010 (hereafter referred to as years 1991 to 2009). The study design was approved by the Research Ethics Board of Sunnybrook Health Sciences Centre.

\section{Data sources}

We collected data from population-based administrative claims databases of the Institute for Clinical Evaluative Sciences. Data on vascular trauma events were obtained from the Canadian Institute for Health Information Discharge Abstract Database. We used diagnostic codes from both the clinical modification of the International Classification of Diseases, 9th revision (ICD-9-CM) and the International Statistical Classification of Diseases and Related Health Problems, 10th revision (ICD-10) to identify vascular injury cases because Canadian hospitals began using ICD-10 codes in 2001. We identified transport-related injuries using the ICD-9-CM codes for external mechanism of injury and the ICD-10 codes for external cause of morbidity and mortality. Cases without these codes constituted non-transport-related injuries. The Registered Persons Database was used to identify individuals who had accessed the Ontario health care system (i.e., the contact files) - population estimates based on contact files corresponded well with actual population census estimates.

In a previous assessment of the validity of vascular injury coding using ICD-10 in the administrative databases, ${ }^{6}$ the positive predictive value of an ICD-10 code for vascular injury being confirmed by direct chart audit was $95 \%$.

\section{Outcome measures}

The primary outcome measure was the annual rate of hospital admissions for vascular injuries per 100000 population in Ontario from 1991 to 2009. Secondary outcomes included rates stratified by sex, age, anatomic site of injury, mechanism of injury, economic status and geographic location. Each vascular (arterial, venous or both) injury event was used as a unit of analysis for rate calculation. Because the number of hospital admissions and vascular injuries was almost equal, we defined a vascular event as a single hospital admission (including transfers) regardless of the number of vascular injuries per patient. The rate of vascular injury events was calculated as the annual number of vascular injury events per 100000 population.

Patients were categorized based on their age at the time of injury ( $<15,15-24,25-64$ and $\geq 65$ yr). Hospital admission rates for each subgroup were calculated and normalized by dividing the number of admissions by the age-stratified popula- tion estimates of Ontario for the relevant period. The hospital admission rates by sex were calculated similarly, using sexstratified population estimates. The anatomic sites assessed for vascular injury events included the neck, thorax, abdomen, upper limbs and lower limbs. Economic status was determined based on neighbourhood income quintiles (low $=$ income quintiles $1-2$; high $=$ income quintiles $3-5$ ). Geographic location was the place of primary residence (urban or rural); the location was determined based on the forward sortation area of Ontario, a geographic region wherein all postal codes start with the same 3 digits. The population estimates for each year were obtained from the Ontario Ministry of Health and LongTerm Care, which defined the population as the number of people accessing health services in Ontario each year.

\section{Statistical analysis}

To assess trends in rates of hospital admissions for vascular injury, we used time-series analysis using exponential smoothing models. ${ }^{7}$ Time-series analyses use various techniques to model autocorrelation in temporally sequenced data. In brief, the Schwarz-Bayesian criteria were used to estimate the best model fit. Stationarity was assessed using the autocorrelation function and the augmented Dickey-Fuller test. Autocorrelation, partial autocorrelation and inverse autocorrelation functions were further assessed for model parameter appropriateness and seasonality. The presence of white noise was assessed by examining autocorrelations at various lag points using the Ljung-Box $\chi^{2}$ statistic. Spectral analysis was used to detect significant seasonality of hospital admissions over the study period, and data were presented using spectral density plots. White noise was detected using the Fisher kappa and Bartlett-Kolmogorov-Smirnov tests.

Rates of hospital admission for vascular injury were calculated for population subgroups stratified by sex, age, anatomic site of injury, mechanism of injury, economic status and geographic location. Differences in percentages were assessed using the $\chi^{2}$ test. All $p$ values were 2 -sided, with a significance level of 0.05 . All statistical analyses were conducted using SAS statistical software version 9.2. Descriptive statistics were used to assess the geographic variation in the distribution of hospital admission rates based on Local Health Integration Networks between Apr. 1, 2007, and Mar. 31, 2010.

\section{Results}

We identified 8252 hospital admissions for vascular trauma. Most patients were male (78.8\%), aged 25-64 years (59.2\%), had a high economic status $(51.1 \%)$ and resided in an urban area $(82.4 \%)$ (Table 1). In terms of mechanism of injury, 1819 $(22.0 \%)$ were transport-related injuries. The annual rate declined significantly over the study period, from 3.3 per 100000 in 1991 to 2.7 per 100000 in $2009(p<0.01)$ (Figure 1).

\section{Sex}

The annual rate of vascular injuries decreased significantly $(p \leq 0.01)$ among males and females (Figure 2A). The annual 
rate among males was about fourfold higher than that among females $(5.7$ v. 1.5 per 100000$)$. A significant variation was observed between the site of injury and patient sex $(p<0.01)$ (Appendix 1, available at www.cmajopen.ca/content/4/2/ E309/suppl/DC1). More injuries to upper limbs occurred among males $(n=3548,54.5 \%)$ than among females $(n=739$, $42.3 \%$ ), and more abdominal vascular injuries occurred among females $(n=291,16.7 \%)$ than among males $(n=734$, $11.3 \%)(p<0.01)$.

\section{Age}

The annual rate of vascular injuries decreased significantly from 1991 to 2009 in the 3 youngest groups (Figure 2B): from 1.3 to 0.5 per 100000 among patients aged less than 15 years $(p=0.04)$, from 5.9 to 4.7 per 100000 among those 15-24 years $(p=0.03)$ and from 3.7 to 2.9 per 100000 among those $25-64$ years $(p<0.01)$. There was no significant change in the rate among patients 65 and older $(p=0.8)$. Although the over-

\section{Table 1: Characteristics of patients admitted to hospital with} vascular injuries, Ontario, 1991-2010

\begin{tabular}{|lc|}
\hline Characteristic & $\begin{array}{c}\text { No. (\%) of hospital } \\
\text { admissions } \\
n=8252\end{array}$ \\
\hline Sex & $6506(78.8)$ \\
\hline Male & $1746(21.2)$ \\
\hline Female & \\
\hline Age group, yr & $493(6.0)$ \\
\hline$<15$ & $2018(24.5)$ \\
\hline $15-24$ & $4888(59.2)$ \\
\hline $25-64$ & $853(10.3)$ \\
\hline$\geq 65$ & \\
\hline Site of injury & $826(10.0)$ \\
\hline Neck & $741(9.0)$ \\
\hline Thorax & $1025(12.4)$ \\
\hline Abdomen & $4287(52.0)$ \\
\hline Upper limbs & $1373(16.6)$ \\
\hline Lower limbs & \\
\hline Mechanism of injury & $1819(22.0)$ \\
\hline Transport-related cause & $6433(78.0)$ \\
\hline Other causes & \\
\hline Economic status ${ }^{*}$ & $3944(47.8)$ \\
\hline Low & $4220(51.1)$ \\
\hline High & $8797(82.4)$ \\
\hline Missing data & \\
\hline Geographic location & \\
\hline Rural & \\
\hline Urban & \\
\hline Missing data & \\
\hline *Low = neighbourhood income quintiles 1.2$)$ \\
\hline
\end{tabular}

all proportion of hospital admissions was highest among patients 25-64 years old, the annual rate per 100000 was highest among patients 15-24 years (6.6), as compared with 1.1 among patients less than 15 years, 3.8 among those 25-64 and 2.9 among those 65 and older.

Significant intergroup differences were observed in the number of hospital admissions by site of injury. The distribution of injury sites was relatively similar in the 3 younger groups except for thoracic and abdominal injuries, which were less frequent in the youngest group (Appendix 1). Patients 65 years and older differed significantly from patients in the younger groups $(p<0.01)$ : they had the highest number of vascular injuries in the thorax $(n=109$, $12.8 \%)$, abdomen $(n=143,16.8 \%)$ and lower limbs $(n=224$, $26.2 \%)$ and the lowest number of injuries in the upper limbs $(n=290,34.0 \%)$.

\section{Anatomic site of injury}

Upper limbs were the most common injury site (52.0\%), followed by lower limbs (16.6\%), abdomen (12.4\%), neck $(10.0 \%)$ and thorax $(9.0 \%)$ (Table 1$)$. The annual rate per 100000 declined significantly from 1991 to 2009 for injuries to the neck (from 0.34 to $0.26 ; p=0.03$ ), the thorax (from 0.32 to $0.26 ; p=0.03$ ), the upper limbs (from 1.7 to $1.34 ; p=0.02$ ) and the lower limbs (from 0.57 to $0.4 ; p<0.01$ ), but not for abdominal vascular injuries (from 0.36 to $0.45 ; p=0.7$ ) (Figure $2 \mathrm{C}$ ). Injuries to the upper limbs were associated with the highest annual rate (1.8 per 100000$)$; the rate of injury at other sites was about fourfold lower (0.43 per 100 000). Appendix 1 shows the distribution of population subgroups based on the number of hospital admissions for different sites of injury.

\section{Mechanism of injury}

The annual rate of transport-related vascular injuries remained stable over the study period (0.68 to 0.62 per 100000 ; $p=1.0)$, whereas the rate of injuries from other causes declined significantly from 2003 to 2009 (from 2.8 to 2.1 per $100000 ; p<0.01$ ) (Figure 2D). The annual rate of non-

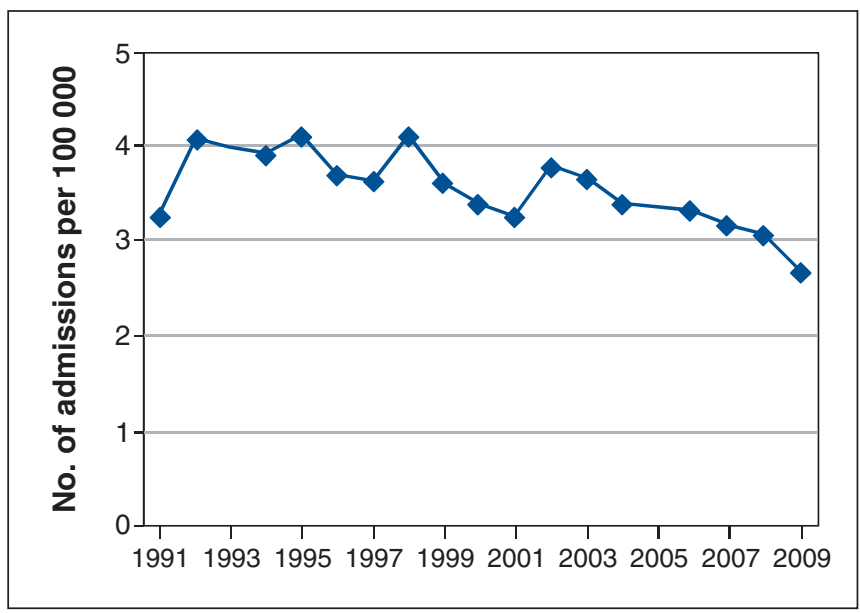

Figure 1: Annual rate of hospital admissions for vascular injuries per 100000 in Ontario, 1991-2009. 
transport-related injuries was more than threefold higher than that of transport-related injuries (2.8 v. 0.8 per 100000$)$. Moreover, the distribution of injury sites by mechanism of injury varied significantly $(p<0.01)$ (Apppendix 1$)$. The most common sites of transport-related injury were lower limbs $(n=485,26.7 \%)$, the abdomen $(n=464,25.5 \%)$ and the tho$\operatorname{rax}(n=403,22.0 \%)$. For injuries from other causes, the most common site was upper limbs $(n=4038,62.8 \%)$.

\section{Economic status}

The annual rate of vascular injuries declined significantly over the study period in both economic status groups (low: from 3.7 to 3.1 per 100000 ; and high: from 3 to 2.4 per 100000 ) $(p<0.01$ for each) (Figure 2E). Although the overall proportion of hospital admissions was higher among patients with a high economic status $(51.1 \%$ v. $47.8 \%)$, the annual rate was higher among patients with a low economic status (4.2 v. 3.1
A

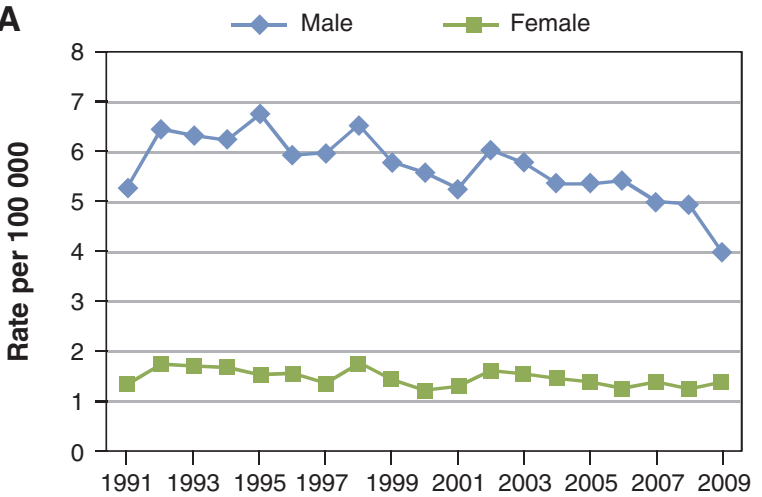

C $\longrightarrow$ Neck $\quad \longrightarrow$ Upper limb $\rightarrow$ Thorax $\rightarrow$ Lower limb

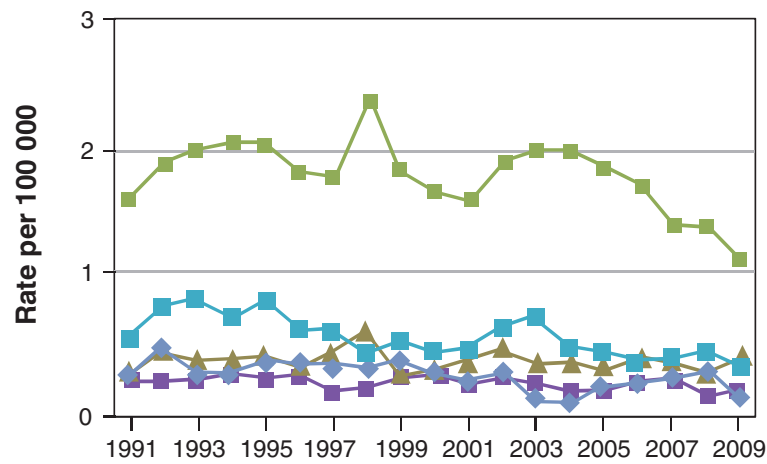

E

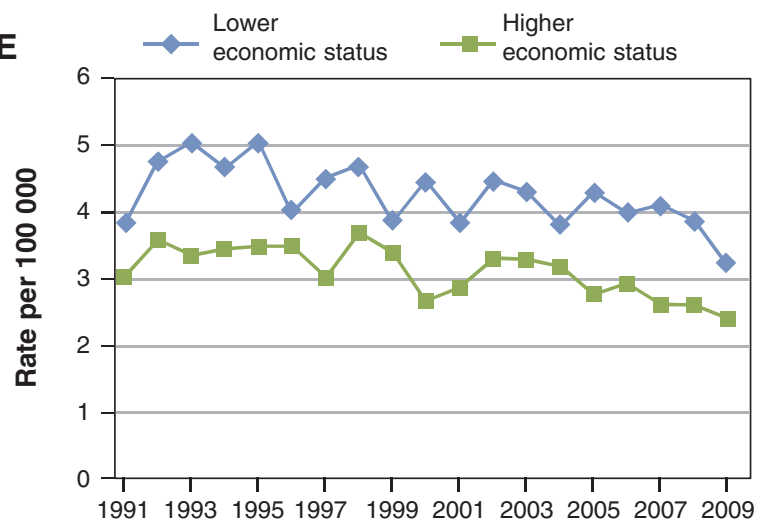

B

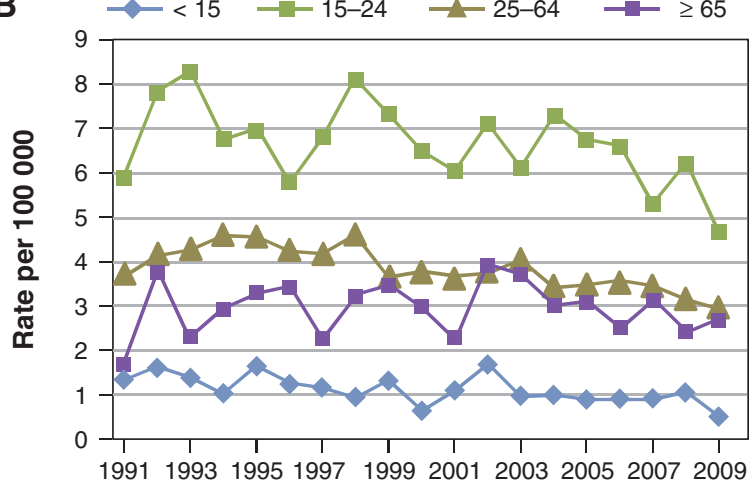

D

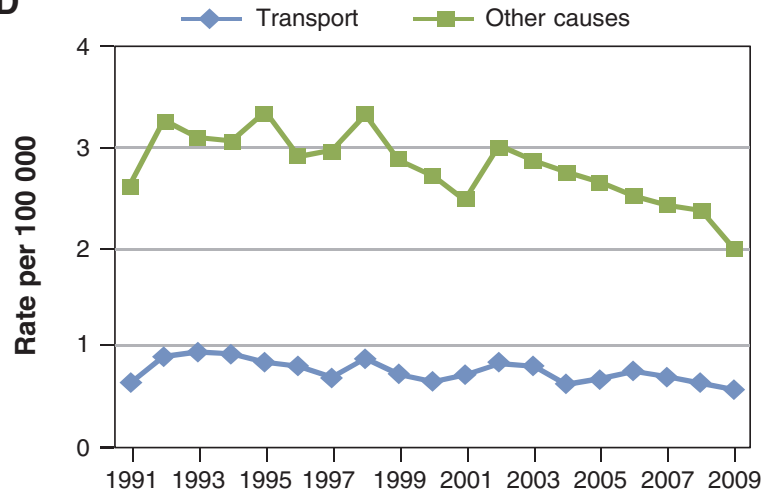

$\mathbf{F}$

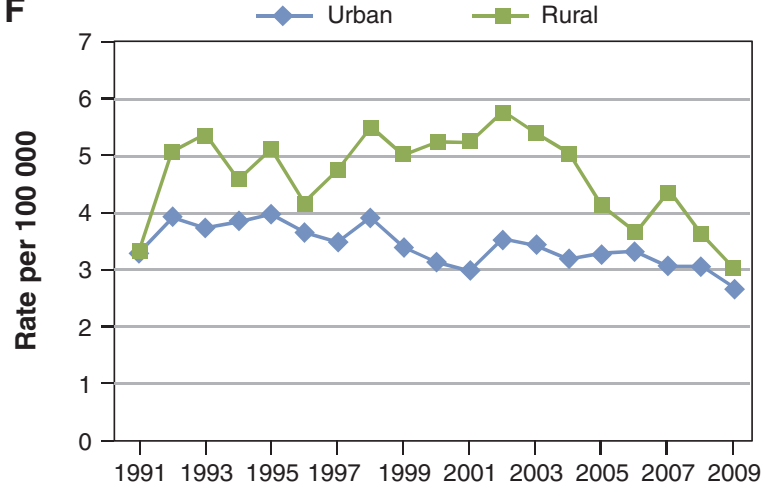

Figure 2: Annual rate of hospital admissions for vascular injuries by $(A)$ sex, (B) age group, (C) anatomic site of injury, (D) mechanism of injury, $(E)$ economic status and $(F)$ geographic location. 
per 100 000). No significant differences were observed in the proportion of hospital admissions by injury site between the 2 groups $(p=0.1)$ (Appendix 1).

\section{Geographic location}

Overall, the annual rate of vascular injuries decreased over time among patients in urban locations (from 3.2 to 2.6 per 100000 ; $p<0.01)$; the rate remained stable in the rural population $(p=$ 0.6). A nonsignificant declining trend was observed in the rural population from 2003 to 2009 (from 5.3 to 3 per 100 000) (Figure $2 \mathrm{~F}$ ). The rates by injury site differed significantly based on geographic location $(p<0.01$; Appendix 1). Although the overall proportion of hospital admissions was higher in urban areas $(82.4 \%$ v. $17.4 \%)$, the annual rate was higher in rural areas (4.6 v. 3.4 per 100000$)$.

\section{Seasonal variation}

When we analyzed quarterly temporal trends in the annual rates of vascular injuries, we observed significant seasonal variations in the form of annual peaks occurring during the summer months (June, July and August; $p<0.01$ ) (Figure 3).

\section{Health region}

The annual rates of vascular injury by health region, based on Local Health Integration Networks, are shown in Figure 4. The highest admission rates (range 13.01-13.48 per 100000 ) were observed in the North Simcoe Muskoka and the Hamilton Niagara Haldimant Brant health regions.

\section{Interpretation}

Our retrospective analysis provides an important insight into vascular injuries in Canada. We observed a decreasing temporal trend in hospital admissions for vascular injuries from 1991 to 2009. The injuries were most common among males, patients aged 25-64 years, those with a high economic status and those residing in urban areas. In contrast, the annual rates were highest among males, patients aged 15-24 years, those with a low economic status and those residing in rural areas. The upper limb was the most common injury site, and most injuries were due to non-transport-related causes. The numbers of injuries to the abdomen and thorax were less than those involving the upper and lower limbs; however, the annual rate declined for all injury sites except the abdomen. This may have been because the nature of injury and the force necessary to cause abdominal vascular injury is primarily blunt trauma, such as motor vehicle collisions, ${ }^{8}$ and the annual rate of transport-related vascular injuries was relatively stable over time.

The stability observed in the rate of transport-related injuries is consistent with the high number of motor vehicle collisions and the lack of reduction in global deaths due to road-traffic crashes, most of which involve young men. ${ }^{9-14}$ The proportion of non-transport-related vascular injuries in our study was similar to that reported in the United States and Latin America, ${ }^{15-18}$ but higher than that reported in Europe, Australia and other developing countries. ${ }^{12,14}$ Certain factors that may contribute to a sustained high risk of transport-related injuries in Canada are the increasing number of vehicles on the road, variable road infrastructure in rural areas, reduced use of safety precautions and alcohol consumption. ${ }^{11,19,20}$

We did not observe a significant decline in the incidence of vascular injuries among older and rural populations. Reportedly, rural patients with vascular injury exhibit more serious injuries and a twofold higher rate of death than such patients with nonvascular injuries; they also require longer hospital stays and higher hospital costs than their urban counterparts do. ${ }^{15}$ Our findings are concordant with those of a previous study in Canada, which reported an association between increased injury incidence and rurality, age and male sex. ${ }^{11}$ Even in a developed country such as Canada, rural populations are at

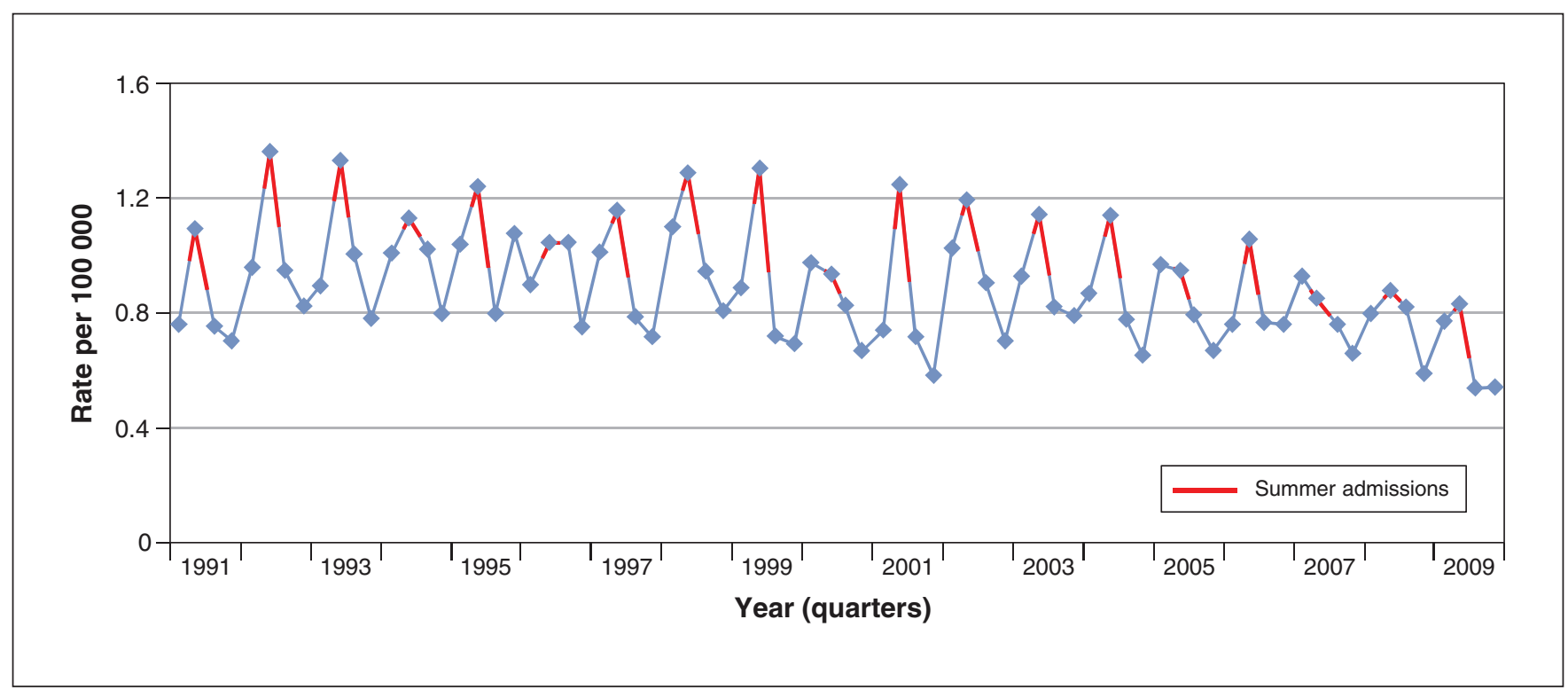

Figure 3: Seasonal variation in annual rates of hospital admissions for vascular injuries. Fisher kappa: $p<0.01$; Bartlett-Kolmogorov-Smirnov test: $p<0.01$. 


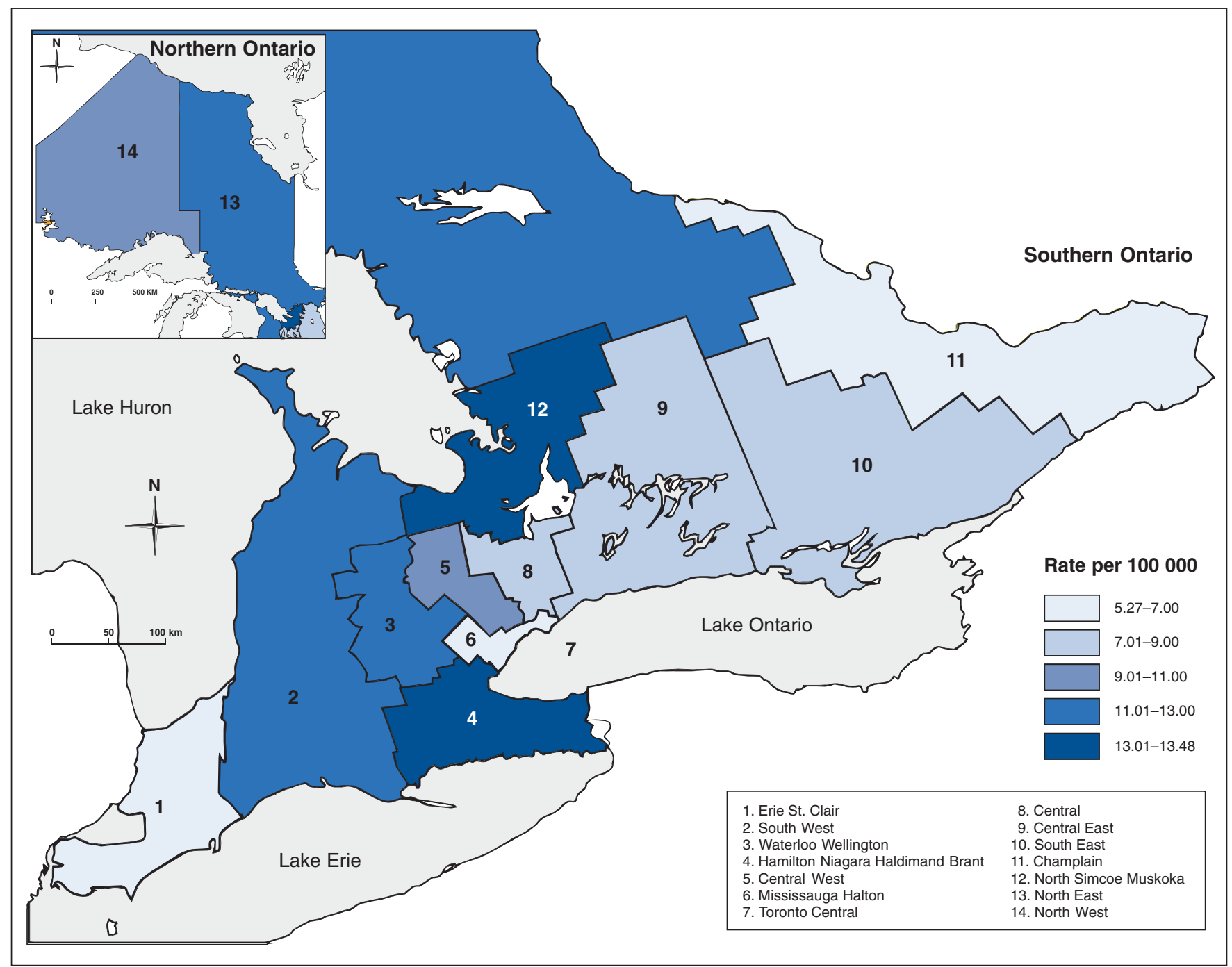

Figure 4: Geographic distribution of annual rates of hospital admissions for vascular injuries by health region in Ontario, 2007-2009.

increased risk of injuries and require improved access to emergency care and transportation facilities to prevent fatalities. ${ }^{21,22}$

The incidence of vascular injuries was higher among people with a low economic status than among those with a high economic status. This finding corroborates previous reports of higher injury rates in the low-income segment of the population in Canada. ${ }^{23,24}$ Despite a decreasing trend in vascular injury, the sustained risk of vascular trauma in subgroups of populations must be addressed.

Analysis of quarterly based temporal trends during the study consistently identified peaks in the summer months. Summer holidays, accompanied by the absence of inclement weather, favour increased travel and transportation and encourage outdoor activities, thereby increasing the potential for vascular injuries.

\section{Limitations}

Although the coding assessed in 2 hospitals was accurately concordant with the chart reviews, it may not have reflected the practice at all the hospitals included in the study. Undercoding or incorrect coding could cause underestimation of injury rates. Geographic location was based on the place of residence of patients rather than on the location where the injury occurred, because the latter was unavailable in the databases. The duration of hospital admission was not analyzed, and future studies could investigate the evolution of inpatient management practices over time.

The advancement and proliferation of noninvasive diagnostic imaging during the course of the study (e.g., improvements and greater availability of computed tomography angiography) may have contributed to an underestimation of the decrease of vascular injury in time. This information was not collected and should be collected in future studies.

Several factors govern the mechanism of injuries. For example, injuries due to motor vehicle collisions are known to be disproportionately higher in rural areas than in urban areas. ${ }^{25}$ Given that the majority of people in Ontario reside in urban areas, ${ }^{26}$ the incidence of transport-related injuries in our study 
was relatively low compared with the rate of non-transportrelated injuries. Yet over time, there was no decline in the incidence of transport-related injuries. Assessing the treatment protocols for transport-related injuries could be looked at in the future studies, preferably in a population that is at increased risk of motor vehicle crashes (e.g., rural).

\section{Conclusion}

Our study provides population-based evidence of a declining trend in the annual rate of hospital admissions for vascular injuries in Ontario from 1991 to 2009. The annual rate of vascular injuries was highest among young men, those with a low economic status and those residing in rural areas. The incidence of non-transport-related vascular injuries was higher than that of transport-related vascular injuries. Our findings have important implications for public health and the development of injuryprevention strategies, particularly for population subgroups at a high risk of vascular injury.

\section{References}

1. Polinder S, Haagsma JA, Toet H, et al. Epidemiological burden of minor, major and fatal trauma in a national injury pyramid. Br 7 Surg 2012;99(Suppl 1):114-21.

2. Polinder S, Meerding WJ, Mulder S, et al. Assessing the burden of injury in six European countries. Bull World Health Organ 2007;85:27-34.

3. Vles WJ, Steyerberg EW, Essink-Bot ML, et al. Prevalence and determinants of disabilities and return to work after major trauma. 7 Trauma 2005;58:126-35.

4. Meerding WJ, Looman CW, Essink-Bot ML, et al. Distribution and determinants of health and work status in a comprehensive population of injury patients. 7 Trauma 2004;56:150-61.

5. Facts on injury. Ottawa: Public Health Agency of Canada; 2006. Available: www.phac-aspc.gc.ca/injury-bles/facts-eng.php (accessed 2014 May 14).

6. Altoijry A, Al-Omran M, Lindsay TF, et al. Validity of vascular trauma codes at major trauma centres. Can 7 Surg 2013;56:405-8.

7. Pindyck RS, Rubinfield DL. Econometric models and economic forecasts. 4th ed. New York: Irwin McGraw-Hill; 1998.

8. Coimbra R, Hoyt DB. Vascular trauma: epidemiology and natural history. In: Cronenwett JL, Johnston KW, editors. Rutherford's vascular surgery. 7th ed. Philadelphia: Saunders Elsevier; 2010.

9. Global status report on road safety 2013. Geneva: World Health Organization; 2013. Available: www.who.int/violence_injury_prevention/road_safety_status/2013/en/ (accessed 2014 May 14)

10. Garwe T, Mallonee S, Stewart K, et al. The magnitude of major trauma in Oklahoma. 7 Okla State Med Assoc 2004;97:70-4.

11. How healthy are rural Canadians? An assessment of their health status and health determinants. Ottawa: Canadian Institute for Health Information; 2006. Available: https://secure.cihi.ca/free_products/rural_canadians_2006_report_e.pdf (accessed 2016 Apr. 13).

12. Fingerhut A, Leppaniemi AK, Androulakis GA, et al. The European experience with vascular injuries. Surg Clin North Am 2002;82:175-88.

13. Caps MT. The epidemiology of vascular trauma. Semin Vasc Surg 1998;11: 227-31.

14. Gupta R, Rao S, Sieunarine K. An epidemiological view of vascular trauma in Western Australia: a 5-year study. ANZ 7 Surg 2001;71:461-6.
15. Oller DW, Rutledge R, Clancy T, et al. Vascular injuries in a rural state: review of 978 patients from a state trauma registry. 7 Trauma 1992;32:740-5.

16. Morales-Uribe CH, Sanabria-Quiroga AE, Sierra-Jones JM. Vascular trauma in Colombia: experience of a level I trauma center in Medellin. Surg Clin North Am 2002;82:195-210.

17. Sonneborn R, Andrade R, Bello F, et al. Vascular trauma in Latin America: a regional survey. Surg Clin North Am 2002;82:189-94.

18. Drapanas T, Hewitt RL, Weichert RF III, et al. Civilian vascular injuries: a critical appraisal of three decades of management. Ann Surg 1970;172:351-60.

19. Canadian motor vehicle traffic collision statistics. Ottawa: Transport Canada; 2011. Available: www.tc.gc.ca/media/documents/roadsafety/TrafficCollision Statisitcs_2011.pdf (accessed 2015 May 14).

20. Skog OJ. Alcohol consumption and fatal accidents in Canada, 1950-98. Addiction 2003;98:883-93.

21. Simons R, Brasher P, Taulu T, et al. A population-based analysis of injuryrelated deaths and access to trauma care in rural-remote northwest British Columbia. 7 Trauma 2010;69:11-9.

22. Gomez D, Berube $M$, Xiong $W$, et al. Identifying targets for potential interventions to reduce rural trauma deaths: a population-based analysis. 7 Trauma 2010;69:633-9.

23. Faelker T, Pickett W, Brison RJ. Socioeconomic differences in childhood injury: a population based epidemiologic study in Ontario, Canada. Inj Prev 2000;6:203-8

24. Oliver L, Kohen D. Neighbourhood income gradients in hospitalisations due to motor vehicle traffic incidents among Canadian children. Inj Prev 2009;15:163-9.

25. Zwerling C, Peek-Asa C, Whitten PS, et al. Fatal motor vehicle crashes in rural and urban areas: decomposing rates into contributing factors. Inj Prev 2005;11:24-8.

26. Population, urban and rural, by province and territory (Ontario). Ottawa: Statistics Canada; 2011. Available: http://www.statcan.gc.ca/tables-tableaux/sum-som/101/ cst01/demo62g-eng.htm (accessed 2015 Dec. 11).

Affiliations: Li Ka Shing Knowledge Institute (Altoijry, Mamdani), St. Michael's Hospital, University of Toronto, Toronto, Ont.; Division of Vascular Surgery (Altoijry, Al-Omran), Department of Surgery, King Saud University, Riyadh, Saudi Arabia; Division of Vascular Surgery (AlOmran), St. Michael's Hospital; Division of Vascular Surgery (Johnston, Lindsay), Toronto General Hospital, University of Toronto, Toronto, Ont.

Contributors: Mohammed Al-Omran, Muhammad Mamdani and Wayne Johnston participated in the study conception. Thomas Lindsay and Muhammad Mamdani participated in the study design and study supervision. Abdulmajeed Altoijry performed the data collection and statistical analysis. Abdulmajeed Altoijry drafted the manuscript, and all of the authors revised it critically for important intellectual content. All of the authors approved the final version to be published and agreed to act as guarantors of the work.

Funding: No external funding was received for this study.

Disclaimer: This study was performed using data provided by the Institute for Clinical Evaluative Sciences (ICES). ICES is funded by an annual grant from the Ontario Ministry of Health and Long-Term Care (MOHLTC). No endorsement by ICES or the Ontario MOHLTC is intended or should be inferred.

Supplemental information: For reviewer comments and the original submission of this manuscript, please see www.cmajopen.ca/content/4/2/ E309/suppl/DC1 